\title{
CONTRIBUIÇÕES DA REFERENCIAÇÃO PARA O ENSINO- APRENDIZAGEM DE LÍNGUA PORTUGUESA, COM ÊNFASE NA NATUREZA ARGUMENTATIVA DA LINGUAGEM
}

\author{
CONTRIBUTION OF REFERENTIALITY TO PORTUGUESE \\ TEACHING AND LEARNING, EMPHASIZING THE \\ ARGUMENTATIVE NATURE OF LANGUAGE
}

\author{
Valdinar Custódio Filho ${ }^{1}$
}

\begin{abstract}
Resumo: Este artigo tem como objetivo mais amplo propor uma reflexão sobre as relações entre linguística textual e ensino e aprendizagem de língua portuguesa. Parte-se do postulado assumido pela linguística textual praticada no Brasil na atualidade, que compreende a argumentação como um processo inerente à linguagem, já que em todos os textos há um direcionamento do locutor para mudar, em algum nível, o estado do interlocutor (CAVALCANTE et al., 2020). Com base nisso, elegemos o processo da referenciação como estratégia a ser explorada em práticas pedagógicas, propondo uma análise de duas atividades em que a construção da coerência passa pela percepção da argumentatividade dos referentes. Acreditamos que as atividades sugeridas se pautam pela promoção do aprendizado eficaz, no plano tanto da visada argumentativa quanto da dimensão argumentativa (AMOSSY, 2011). Além disso, ao levar em conta a ação do aprendiz sobre os textos, em vez de se ligar ao caráter meramente expositivo de mecanismos de coesão referencial, essas atividades permitem a renovação (a nosso ver, urgente) do trabalho pedagógico com estratégias de textualização.
\end{abstract}

Palavras-chave: Referenciação. Argumentação. Ensino de língua portuguesa.

\begin{abstract}
The broader purpose of this article is to suggest a reflection about the relation between text linguistics and Portuguese teaching and learning. It puts as a starting point the postulate assumed by text linguistics that takes place in Brazil nowadays, which comprehends argumentation as an inherent process of any language, once all texts have a direction, posed by locutors, to change, at some level, the interlocutor's state of being (CAVALCANTE at al., 2020). Based on this, we elect the process of referentiality as the strategy to be explored in pedagogical practices, proposing an analysis of two activities in which the building of coherence depends on the argumentative perception of the referents. We believe that these activities show the promotion of effective learning, in both the levels of argumentative aim and argumentative dimension (AMOSSY, 2011). Furthermore, these activities, taking account the apprentice action over texts, instead of putting attention only to the merely expositive view of mechanisms of referential cohesion, aloud the renovation (urgent, in our opinion) of the pedagogical work with textualization strategies.
\end{abstract}

Keywords: Referentiation. Argumentation. Portuguese Teaching.

\section{Introdução}

\footnotetext{
${ }^{1}$ Professor do Curso de Letras do Centro de Humanidades da Universidade Estadual do Ceará, Fortaleza-CE, Brasil. E-mail: valdinar.filho@uece.br.
} 


\section{PERcursos Linguísticos • Vitória (ES) •v. 11 •n. 29 • 2021 • ISSN: 2236-2592 • Dossiê temático $\bullet O$ texto na pesquisa e no ensino: conhecimentos, práticas e desafios na contemporaneidade •}

Nas discussões sobre ensino de língua portuguesa realizadas nas últimas quatro décadas no Brasil ${ }^{2}$, tem-se salientado a importância de as práticas de aprendizagem tomarem como elemento central o texto, entendido como instanciação das semioses e da interação na qual diversos aspectos - discursivos, interacionais, pragmáticos, cognitivos, gramaticais, semióticos - confluem para que haja a produção e compreensão de sentidos. Falar de texto, obviamente, pressupõe, em princípio, considerar um conjunto de perspectivas teóricas calcadas na enunciação, que tomam como ponto de partida a explicação dos fenômenos de linguagem com base no uso efetivo de enunciados, atrelados a sujeitos ancorados numa situação sócio-histórica. Dentre essas perspectivas, a linguística textual (doravante LT) desponta com proeminência, ao considerar um conjunto de parâmetros analíticos simultaneamente singulares e interdisciplinares ${ }^{3}$ como elementos responsáveis pela instauração da coerência.

Com a raiz fincada na LT (particularmente, a LT praticada no Brasil), este trabalho propõe uma reflexão sobre possíveis contribuições da perspectiva teórica da referenciação para o trabalho pedagógico com vistas a desenvolver as habilidades de argumentação de aprendizes na educação básica. Há, portanto, três eixos teóricos definidores do percurso que será trilhado aqui: argumentação, referenciação e ensino.

No que toca à argumentação, pautamo-nos pela proposta de Cavalcante et al. (2020), que estabelece uma interface entre a LT brasileira e a teoria da argumentação no discurso, de Amossy (2011, 2017), a fim de sustentar que o aspecto argumentativo da linguagem é a condição primeira para a ocorrência do processo interacional mediado por textos.

No que diz respeito à referenciação, consideramos a proeminência do fenômeno como estratégia textual-discursiva para a construção da coerência (CAVALCANTE, CUSTÓDIO FILHO e BRITO, 2014), a partir do que os objetos de discurso (ou referentes) construídos na interação revelam o trabalho de interlocutores que lidam com a materialidade semiótica e com as várias instâncias intervenientes nessa materialidade.

No que tange ao ensino ${ }^{4}$, propomos uma breve discussão sobre o modo como a referenciação costuma aparecer em livros didáticos de língua portuguesa, para sugerirmos que esse trabalho precisa passar por uma renovação que faça jus à produção de conhecimento na

\footnotetext{
${ }^{2}$ Alguns expoentes dessa discussão são Geraldi (1997), Antunes (2003, 2010), Koch e Elias (2006, 2009, 2018) e Suassuna (1995).

${ }^{3}$ Para considerações sobre o conceito de texto como objeto científico da LT e as relações interdisciplinares estabelecidas na área, sugerimos a leitura de Cavalcante e Custódio Filho (2010), Cavalcante et al. (2016) e Cavalcante et al. (2019).

${ }^{4}$ Caberia, ainda, propor uma reflexão sobre a relação entre a LT e prática docente, especialmente em cotejo com a Base nacional comum curricular (BRASIL, s/d). Em virtude da limitação de espaço, deixamos a discussão para outra ocasião.
} 


\section{PERcursos Linguísticos • Vitória (ES) •v. 11 •n. 29 • 2021 • ISSN: 2236-2592 • Dossiê temático $\bullet O$ texto na pesquisa e no ensino: conhecimentos, práticas e desafios na contemporaneidade •}

área, que avançou bastante em relação às primeiras considerações sobre coesão referencial (KOCH, 1999).

Cada um desses eixos responde por uma seção deste artigo, ao que posteriormente se acrescenta uma seção analítica na qual se discute a pertinência de duas atividades pedagógicas focadas em habilidades atinentes à construção de referentes, compreendida como processo argumentativo constitutivo das práticas de compreensão e produção.

\section{Linguística textual e argumentação - o panorama atual}

A linguística textual tem uma tradição de propor a análise de seus fenômenos com vistas a apontar características argumentativas. Apotheloz e Reichler-Béguelin (1995), por exemplo, em seu texto seminal sobre a recategorização referencial, falam em uma eventual função argumentativa das recategorizações lexicais explícitas. Do mesmo modo, Koch (2005, p. 3435) diz que "O sujeito, por ocasião da interação verbal, opera sobre o material linguístico que tem à sua disposição, realizando escolhas significativas para representar estados de coisas, com vistas à concretização de sua proposta de sentido" (grifo nosso).

Para além da referenciação, outros trabalhos em LT dos anos 2000 e dos anos 2010 dissertam sobre a natureza argumentativa das intertextualidades (KOCH, BENTES e CAVALCANTE, 2007, FORTE, 2013, CARVALHO, 2018), dos mecanismos de articulação (KOCH e ELIAS, 2018), bem como a possibilidade de construção de quadros tópicos de textos com sequência argumentativa predominante ${ }^{5}$ (SÁ, 2018).

Em muitos desses e em outros estudos, entende-se que as diversas estratégias de textualização apresentam uma função argumentativa, a qual revela determinado ponto de vista ${ }^{6}$, do locutor ou de alguma instância por ele acionada para compor o texto. Nesse viés, a argumentação ocupa um papel subordinado à estratégia. Por exemplo, quando, nessa perspectiva, afirma-se que uma expressão referencial pode assumir um papel argumentativo (como se vê em CAVALCANTE, CUSTÓDIO FILHO e BRITO, 2014), mostra-se que, em alguns casos, o caráter explicitamente avaliativo da expressão contribui para a construção argumentativa do texto.

Nos últimos cinco anos, a LT praticada no Brasil tem defendido uma conexão forte entre os parâmetros analíticos da disciplina e os pressupostos da teoria da argumentação no discurso

\footnotetext{
${ }^{5} \mathrm{O}$ estudo sobre as sequências textuais (inclusive a argumentativa) se encontra em Adam (2019).

${ }^{6}$ Para uma compreensão mais específica do conceito de ponto de vista, sugerimos a leitura de Cortez e Koch (2013).
} 


\section{PERcursos Linguísticos • Vitória (ES) •v. 11 •n. 29 • 2021 • ISSN: 2236-2592 • Dossiê temático $\bullet O$ texto na pesquisa e no ensino: conhecimentos, práticas e desafios na contemporaneidade •}

$(\mathrm{TAD})^{7}$. Essa postura provoca uma modificação na compreensão sobre o papel da argumentação nas investigações da área. A partir dessa configuração, Cavalcante et al. (2020, p. 30) afirmam que "todo discurso tende a orientar os modos de ver, de pensar e de sentir dos interlocutores"8. Isso implica que a razão de ser de todo texto se assenta na condição de que há um projeto de dizer constitutivamente argumentativo. O locutor que lança mão de um texto, portanto, pretende, em última instância, gerar um ou mais efeitos no interlocutor.

O que o novo paradigma aponta é que a argumentação é bem mais que uma função textual. Não se trata mais de investigar como os fenômenos que competem para a construção da coerência podem ter feição menos ou mais evidentemente argumentativa. Trata-se de compreender que a natureza constitutivamente argumentativa da linguagem define a construção da coerência, por meio da mobilização de estratégias acionadas para promover a interação, o que implica a participação de sujeitos que querem alguma(s) coisa(s) uns dos outros. Para nós, esse modo de encarar o texto, como objeto de pesquisa da LT, gera um conjunto de reflexões que, ao mesmo tempo em que perpetuam a tradição de ligar a LT à argumentação, garantem o avanço científico na medida em que há novas problematizações, novas perguntas teóricas e novos modos de buscar respostas.

Neste artigo, destacamos duas condições decorrentes desta perspectiva: a distinção entre visada argumentativa e dimensão argumentativa, e a agentividade dos sujeitos sociais. Aqui, apresentamos uma breve reflexão teórica sobre essas condições; posteriormente, na seção de análise, elas retornam, como elementos que podem/devem estar presentes na construção de atividades pedagógicas.

Sobre a visada e a dimensão argumentativa, Cavalcante et al. (2020, p. 30), partindo de Amossy, explicam que, "Na visada argumentativa, há estratégia programada de persuasão, pois o objetivo do locutor ao produzir um texto que comporte essa visada é levar o interlocutor a aderir à sua opinião ou tese sobre o tema debatido". Há textos de visada argumentativa entre os gêneros reconhecidos como predominantemente argumentativos. Por exemplo, os textos cujos títulos aparecem a seguir apresentam visada argumentativa.

(1)

Figura 1 - títulos e subtítulos de textos com visada argumentativa

\footnotetext{
${ }^{7}$ Essa interface tem sido difundida especialmente pelos membros do Grupo Protexto, da Universidade Estadual do Ceará (UFC).

${ }^{8}$ A mesma visão encontra-se em Cavalcante et al. (2019).
} 


\title{
PERcursos Linguísticos • Vitória (ES) •v. 11 •n. 29 • 2021 • ISSN: 2236-2592 • Dossiê temático $\bullet O$ texto na pesquisa e no ensino: conhecimentos, práticas e desafios na contemporaneidade •
}

\author{
RICARDO VOLPE E EUGÊNIO GREGGIANIN \\ O teto de gastos deve ser suspenso \\ temporariamente para reforçar as \\ medidas de combate à pandemia? \\ NÃO \\ Propósito é garantir a estabilidade, inclusive para as \\ futuras geraçöes \\ SIMONE DEOS E BRUNO CARAMELLI \\ 0 teto de gastos deve ser suspenso \\ temporariamente para reforçar as \\ medidas de combate à pandemia? SIM \\ Regra é disfuncional, e sabemos que os efeitos da \\ crise se estenderão
}

Fonte: Folha de São Paulo. Disponível em https://www1.folha.uol.com.br/opiniao/. Acesso em 12 abr. 2021.

Os textos correspondentes aos títulos fazem parte de uma seção do jornal Folha de São Paulo chamada "Tendências/Debates". Alguns dos textos dessa seção surgem de uma pergunta que o jornal lança e cuja resposta - sim ou não - equivale a uma tese. No caso ilustrado, um dos textos defenderá que "O texto de gastos deve ser suspenso temporariamente para reforçar os meios de combate à pandemia", e o outro defenderá a tese contrária. A coerência de cada um será construída por meio de uma organização a qual revele estratégias garantidoras do valor da tese defendida. A visada se encontra, justamente, nessa organização com vistas a construir a pertinência de uma tese.

Também há visada argumentativa no exemplo a seguir.

(2)

Figura 2 - exemplo de visada argumentativa em charge

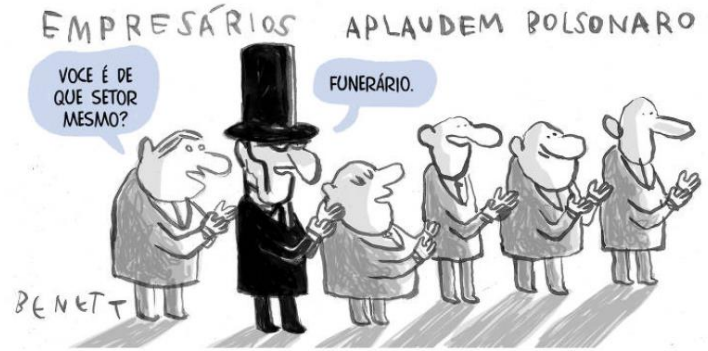

Fonte: Folha de São Paulo. Disponível em https://fotografia.folha.uol.com.br/galerias/1695890190757786-charges-abril-2021. Acesso em 12 abr. 2021.

A charge do exemplo (2) toma como mote a notícia de que alguns empresários aplaudiram o presidente Jair Bolsonaro durante um jantar em abril de 2021, época em que o Brasil passava por um momento crítico da pandemia pelo coronavírus, com números diários de 


\title{
PERcursos Linguísticos • Vitória (ES) •v. 11 •n. 29 • 2021 • ISSN: 2236-2592 • Dossiê temático $\bullet O$ texto na pesquisa e no ensino: conhecimentos, práticas e desafios na contemporaneidade •
}

mortes e infecções bastante elevados. A presença de um "empresário" do setor funerário gera o humor do texto e remete à ideia de que as ações do governo federal, associadas (obviamente) à figura do presidente, ocasionaram inúmeras mortes. Logo, há uma visada argumentativa, traduzida pela tese de que os empresários que aplaudem o presidente compactuam com esse quadro.

Já a dimensão argumentativa

\begin{abstract}
aparece na verbalização que produz um discurso ${ }^{9}$ cujo objetivo declarado é outro e não o argumentativo: um discurso de informação, uma descrição, uma narração cuja vocação é contar o registro de uma experiência vivida em um diário de viagem ou um diário, um testemunho que relata o que o sujeito viu, uma conversa familiar em que os parceiros jogam conversa fora sem a pretensão de fazer triunfar uma tese etc. Portanto, o que é importante é identificar e analisar a maneira como esses discursos destinados a, antes de tudo, informar, escrever, narrar, testemunhar, direcionam o olhar do alocutário para fazê-lo perceber as coisas de uma certa maneira. (AMOSSY, 2011, p. 132, grifo nosso)
\end{abstract}

Há dimensão argumentativa, por exemplo, no vídeo “Amiga falsa no Facebook!”. Nesse esquete, a personagem fala em voz alta enquanto acessa a sua conta de Facebook. A seguir, transcrevemos o trecho inicial dessa fala.

(3) Deixa eu ver aqui... Olha aí o Facebook da demônia! Essa minha amiga é ridícula mesmo, viu? Posta foto no Face como se tivesse (sic) a coisa mais linda do mundo. Se maqueia (sic) mal pra caramba, pelo amor de Deus, parece que levou duas chineladas na cara. O pessoal pensa que bochecha é boca e blush é batom. Hah, é o jeito que tem eu comentar, né? [digita no notebook] "Linda, linda. Coisa linda, ave maria, tá linda demais".

Disponível em https://www.youtube.com/watch?v=hwIqFY5u62c. Acesso em 25 set. 2021.

O exemplo (3), como parte de uma narrativa, não tem a "pretensão de fazer triunfar uma tese", mas mostra uma perspectiva do locutor que tem como objetivo gerar um efeito no interlocutor. Ao mostrar que a personagem faz um comentário (já que "é o jeito") falso na conta de Facebook de uma amiga, pretende-se, por meio do humor, criticar o comportamento recorrente de fazer comentários elogiosos em excesso, que decorrem mais de uma convenção social (comentar fotos de amigos) do que da expressão de uma admiração sincera. Essa crítica embutida na narrativa mostra que, no final das contas, a argumentação está por trás da construção de todo texto, e não apenas na construção de textos evidentemente persuasivos.

Uma vez que o ponto de partida dos textos é uma proposta argumentativa - seja como persuasão direta, seja como persuasão indireta - tem-se que os participantes da interação

\footnotetext{
${ }^{9}$ Em muitos casos (como nessa citação), o que Amossy chama de "discurso" equivale, para muitos teóricos da LT, a "texto".
} 


\section{PERcursos Linguísticos • Vitória (ES) •v. 11 •n. 29 • 2021 • ISSN: 2236-2592 • Dossiê temático $\bullet O$ texto na pesquisa e no ensino: conhecimentos, práticas e desafios na contemporaneidade •}

(locutor e seu(s) interlocutor(es)) assumem papéis que demandam, em algum nível, uma ação estratégica. É nesse sentido que a LT concebe, diferentemente de concepções que apontam para o assujeitamento, que "os sujeitos têm algum poder de mudar a realidade, por isso é possível observar os empreendimentos argumentativos na conjuntura do espaço social regrado por normas institucionais" (CAVALCANTE et al, 2020, p. 15, grifo nosso.).

Há agentividade, por exemplo, quando Ricardo Volpe, Eugênio Greggianin, Simone Deos e Bruno Caramelli (exemplo (1)), instados a defender uma tese sobre a relação entre o teto de gastos e o financiamento de medidas de combate à pandemia, selecionam os argumentos (e o modo de apresentá-los) que figurarão em seus textos, os quais "acontecem" num momento específico da realidade brasileira. Do mesmo modo, o chargista Bennet (exemplo (2)), ao criar uma cena fictícia para o jantar do presidente Bolsonaro com empresários, cria um texto único, com uma voz que reverbera um pensamento compartilhado, mas que tem uma realização singular. Também o criador do esquete sobre comentários no Facebook (exemplo (3)) aborda o assunto a partir de um modo de ver que ganha corpo com a materialidade estruturada por ele.

Nos casos aqui exemplificados, os sujeitos são agentes não porque trazem teses ou pontos de vista originais, mas porque, ao proporem interações (no plano da visada ou da dimensão argumentativa), atualizam temas já conhecidos por meio de um produto singular. Nesse movimento, há campo para se propor a mudança da realidade, seguindo-se o propósito primeiro de provocar algum tipo de reação no interlocutor.

A LT muito tem a contribuir com essa perspectiva de argumentação, na medida em que suas categorias de análise são motivadas "por uma tentativa de explicação para as escolhas textuais pelas quais o sujeito age sobre seu dizer, reelaborando-o a todo instante, negociando-o com os prováveis interlocutores (em seus papéis sociais), para buscar atender a seus propósitos" (CAVALCANTE et al., 2020, p. 15). As instâncias textual-discursivas e os fenômenos que competem para a construção de uma materialidade dotada de sentido são, portanto, elementos evidenciadores do trabalho argumentativo, e é a partir desse viés que devem estar presentes nas práticas de aprendizagem.

\section{Referenciação e argumentação}

A referenciação consiste numa abordagem teórica que investe na condição da referência textual como ação dos interlocutores. Partindo do pressuposto de que o papel primordial da linguagem é permitir que os interlocutores construam versões negociadas da realidade (MONDADA e DUBOIS, 2003), tem-se que os referentes são elaborações, instanciadas no 


\section{PERcursos Linguísticos • Vitória (ES) •v. 11 •n. 29 • 2021 • ISSN: 2236-2592 • Dossiê temático $\bullet O$ texto na pesquisa e no ensino: conhecimentos, práticas e desafios na contemporaneidade •}

texto, que possibilitam aos sujeitos da interação promoverem os sentidos das entidades sobre as quais querem/devem/podem falar. Essas entidades são mostradas de acordo com as possibilidades traçadas pela dinâmica sociodiscursiva em que se encontram.

Esse processo de reelaboração e negociação leva-nos a compreender que os referentes são objetos dinâmicos, passando por modificações dentro de um texto, as chamadas recategorizações ${ }^{10}$. Podemos ver como isso se efetiva a partir da análise do exemplo a seguir.

Trata-se de uma cena de O livro de Henrique, ficção histórica que tem como fio condutor o rompimento, no século XVI, da Inglaterra com o catolicismo europeu vigente e a consequente criação da religião anglicana. Na cena em questão, Henrique VIII, rei da Inglaterra, descobriu recentemente que sua segunda esposa, Ana Bolena, teria cometido adultério, com alguns membros da corte real. Henrique conversa sobre isso com Thomas Cromwell, seu braço direito.

(4)

- Cromwell, o que significa isso, quando uma mulher não consegue sossegar na cama? Oferecendo-se, de todas as maneiras? O que se passa em sua cabeça para fazer uma coisa dessas? [...] Uma única maneira é aquela apta para a procriação de filhos. A Santa Igreja sanciona essa maneira nos dias permitidos. Temo que qualquer homem ou mulher cristã que esteja escravo desses vícios [hábitos sexuais não sancionados pela Igreja] incorrerá em julgamento: o que você diria? Onde uma mulher que não foi criada em um prostíbulo poderia adquirir conhecimento de tais coisas?

- As mulheres conversam entre si - responde Cromwell. Como os homens.

- Mas uma matrona sóbria, religiosa, cujo único dever é ter um filho?

- Suponho que ela talvez queira alimentar o interesse de seu bom esposo, senhor. Para que ele não se aventure no Jardim de Paris ou algum outro lugar de má reputação. Se, digamos, estão casados há muito tempo.

- Mas três anos? Isso é muito?

- Não, senhor.

- Não faz nem três. - Por um momento, o rei esquece que não estamos falando dele, mas de um hipotético inglês temente a Deus, um homem dos bosques ou da lavoura. — Onde ela teria a ideia? — persiste ele. — Como saberia que o homem iria gostar?

Ele engole a resposta óbvia: talvez ela tenha conversado com a irmã, que esteve em sua [do rei] cama. Mas agora o rei já partiu de Whitehall [uma das residências do reil e voltou para o interior, para o camponês de dedos nodosos e sua esposa de avental e touca: o homem que se benze e pede licença ao papa antes de apagar a vela entre os dedos e se voltar solenemente à esposa [...].

Mas um dia, enquanto o camponês se dedica à labuta, o pequeno aprendiz de lenhador entra sorrateiramente e põe sua ferramenta para fora: agora, Joan, diz ele, agora, Jenny, dobre-se sobre a mesa e eu lhe ensinarei algo que sua mãe nunca lhe ensinou. [...] e, quando o honesto camponês volta à casa e a monta naquela noite, ela pensa em uma nova maneira de fazer as coisas, uma maneira mais doce, uma maneira mais suja, uma maneira que faz seus olhos se arregalarem de surpresa e o nome de outro homem irromper em sua boca. E, quando o marido recorda que seu nome na verdade é Henrique, isso não o faz coçar a careca?

MANTEL, Hillary. O livro de Henrique. Rio de Janeiro: Record, 2013, p. 261-262.

${ }^{10}$ Para maior aprofundamento do fenômeno da recategorização referencial, sugerimos a leitura dos trabalhos de Lima (2009), Cavalcante (2011), Custódio Filho (2011) e Cavalcante e Brito (2016). 


\section{PERcursos Linguísticos • Vitória (ES) •v. 11 •n. 29 • 2021 • ISSN: 2236-2592 • Dossiê temático $\bullet O$ texto na pesquisa e no ensino: conhecimentos, práticas e desafios na contemporaneidade •}

$\mathrm{Na}$ conversa entre os dois interlocutores, personagens do romance, os referentes salientes são compreendidos como tendo dupla identidade: ao mesmo tempo em que apresentam caráter genérico, são específicos. O rei inicia a interlocução falando de uma mulher genérica, "que não consegue sossegar na cama”, e, em suas perguntas, tece uma crítica ao comportamento desse tipo de mulher. Cromwell participa da interlocução, procurando justificar o que faria uma mulher casada ter um comportamento sexual mais liberado. Além disso, ao mesmo tempo em que tratam da mulher, os interlocutores também tratam de um marido genérico: "um hipotético inglês temente a Deus", que tem relações sexuais com a esposa dentro do que é permitido pela religião.

Esse caráter genérico das duas entidades está presente nos dois últimos parágrafos, quando o marido é construído como "o homem que se benze e pede licença ao papa", o "honesto camponês", e a mulher que o trai tanto pode ser "Joan" como "Jenny". No último parágrafo, também é apresentado um referente genérico: o amante, “o pequeno aprendiz de lenhador".

Ocorre que, na verdade, os referentes genéricos $<$ marido $>{ }^{11}$ e $<$ mulher $>$ são, ao mesmo tempo, os referentes <Henrique VIII > e <Ana Bolena>. Isso já está implícito no diálogo entre o rei e Cromwell, considerando-se que o tópico da conversa é o adultério da rainha. Contudo, há o reforço dessa dupla identidade quando o rei pergunta: "Mas três anos? Isso é muito?" (o que remete ao tempo em que ele e a rainha estão casados), e quando o narrador completa: "o rei esquece que não estamos falando dele, mas de um hipotético inglês temente a Deus", e depois afirma: "agora o rei já partiu de Whitehall e voltou para o interior, para o camponês de dedos nodosos e sua esposa de avental e touca".

Há, desse modo, um jogo duplo, que vai e volta no que diz respeito ao caráter menos ou mais individual dos referentes, o que é percebido pelos participantes da interação. Estes, sabedores de que o tema do adultério é espinhoso (ainda mais o adultério sofrido pelo rei), o abordam a partir de uma via indireta, tentando falar não dos indivíduos, mas de qualquer um que pudesse passar por isso. Trata-se de uma tentativa que permite a verbalização do tema sem ferir algum brio, mas que não esconde por completo o caso específico de que falam, o que é reforçado pelo narrador quando este sugere que o nome do camponês genérico pode ser "Henrique".

\footnotetext{
${ }^{11}$ Estamos usando os sinais < e > para marcar que o que está em tela não são as expressões em si, mas as entidades construídas, via textualização, para as quais essas expressões (e outras) podem ser usadas.
} 


\section{PERcursos Linguísticos • Vitória (ES) •v. 11 •n. 29 • 2021 • ISSN: 2236-2592 • Dossiê temático $\bullet O$ texto na pesquisa e no ensino: conhecimentos, práticas e desafios na contemporaneidade •}

Nesse jogo, ambos os interlocutores (e o leitor com eles e com o narrador) negociam para que o diálogo possa evoluir. Essa negociação revela as reelaborações e o dinamismo, construídos ao longo da interlocução, característicos da referenciação. Esse é o movimento constitutivo de todos os textos ${ }^{12}$.

Resta lembrar que, conforme assinalam Cavalcante (2011) e Custódio Filho (2011), a construção dos objetos de discurso não está atrelada apenas ao uso de expressões referenciais (sintagmas nominais). No exemplo analisado, essas expressões são importantíssimas para que se compreenda a negociação estabelecida entre os interlocutores, mas elas, por si, não são suficientes. É preciso reconhecer que o texto como um todo - o que comporta sua materialidade e as múltiplas relações que essa materialidade estabelece com instâncias diversas - fornece o campo para que os objetos sofram as recategorizações necessárias. Por exemplo, os enunciados sublinhados (os quais não têm natureza referencial, mas proposicional) também precisam ser levados em conta na construção da referência.

Registre-se, ainda, que tal construção só se efetiva mediante a articulação entre os diversos referentes, o que possibilita a geração de uma rede referencial (MATOS, 2018). O trabalho de fabricação dos sentidos que passa pela referenciação não pode se limitar ao mapeamento de um único referente, pois qualquer entidade construída em um texto se estabelece mediante a relação com outras entidades. Propor uma formulação do referente <marido/Henrique VII> no exemplo (4) não se sustenta se não se fizer, também, uma formulação para o referente <esposa/Ana Bolena> e para outros referentes salientes no excerto.

Finalmente, considerando o que se apontou na seção anterior sobre a relação entre textos e argumentação, é necessário firmar que a construção da referência está sempre atrelada a um projeto de dizer, o qual implica a busca por modificar o modo como o interlocutor pensa, age, sente. Isso vale tanto para a configuração de textos de visada argumentativa quanto para a concretização/percepção da dimensão argumentativa inerente a qualquer texto. A referenciação, como outras estratégias de textualização, está a serviço da argumentação, e, por isso, o papel dos sujeitos no trabalho de formular sentidos é essencial.

\section{Referenciação no ensino - a necessária renovação}

\footnotetext{
${ }^{12} \mathrm{O}$ movimento de negociação é, de fato, constitutivo, mas isso não implica que negociar, em todos os casos, leve à construção harmônica de referentes (ver, sobre isso, CUSTÓDIO FILHO, 2017). Nas interações polêmicas (AMOSSY, 2017), por exemplo, essa harmonia não ocorre.
} 


\section{PERcursos Linguísticos • Vitória (ES) •v. 11 •n. 29 • 2021 • ISSN: 2236-2592 • Dossiê temático $\bullet O$ texto na pesquisa e no ensino: conhecimentos, práticas e desafios na contemporaneidade •}

Reforçando o posicionamento destacado na introdução deste artigo sobre a importância do texto para as práticas de aprendizagem no ensino de língua materna, temos que os critérios analíticos da linguística textual, elementos fundamentais para a manifestação da coerência, devem fazer parte dos programas curriculares das escolas ${ }^{13}$. Além disso, se considerarmos a perspectiva aqui assumida sobre o papel constitutivo da argumentação na configuração dos sentidos mediados por textos, os critérios analíticos precisam ser tratados pedagogicamente como elementos reveladores do projeto de dizer dos sujeitos. O aprendizado necessário à produção e compreensão textual eficazes passa, pois, pela análise e uso de recursos argumentativos vários.

O reconhecimento do papel da referenciação no ensino propicia uma boa oportunidade para refletir sobre a presença das estratégias de textualização nas práticas pedagógicas. Considerando, por exemplo, as práticas mediadas pelos livros didáticos, percebe-se que, de modo geral, nos últimos vinte anos, há pouco espaço destinado a atividades que focalizam a referenciação ${ }^{14}$. Os livros optam por privilegiar as características (muitas vezes vistas de modo estanque) diretamente ligadas à estruturação dos gêneros textuais.

Além do pouco espaço, há outro problema no que diz respeito à necessária atualização teórica das atividades sobre referenciação. Os materiais costumam abordar principalmente a natureza coesiva do fenômeno, propondo atividades didáticas que reiteram as ideias presentes nas primeiras reflexões sobre coesão feitas no Brasil (como se vêm em KOCH, 1999). A título de ilustração ${ }^{15}$, vejamos os exemplos a seguir, que consistem de explicações as quais tocam no fenômeno da construção da referência.

(5)

Figura 3 - Exemplo de explicação em livro didático (1)

No texto, o substantivo Tasmânia é retomado pelos termos: ilha australiana, pequena ilha. Esses termos são utilizados como forma de evitar uma repetição do substantivo. O texto apresenta outro exemplo do mesmo procedimento coesivo. O nome próprio Austrália foi substituído por terra dos cangurus.

O uso de um termo com valor coesivo no lugar de outro(s) elemento(s) do texto, ou até mesmo de uma oração inteira, chama-se substituição.

\footnotetext{
${ }^{13} \mathrm{Na}$ BNCC (BRASIL, s/d), encontram-se, dentre as habilidades referentes à área de língua portuguesa, menções, ainda que às vezes de modo indireto, às estratégias de textualização.

${ }^{14} \mathrm{O}$ mesmo pode ser dito sobre articulação tópica, intertextualidade, metatextualidade, polifonia etc.

${ }^{15}$ Não se pretende, obviamente, que a apresentação de dois exemplos equivalha a um panorama sobre o tratamento da referenciação nos livros didáticos de língua portuguesa. Embora nossa experiência nos diga que uma análise mais substancial chegaria a conclusões parecidas com a que propomos, sabemos que essa afirmação só poderia ser feita de modo mais assertivo mediante uma análise mais substancial.
} 


\section{PERcursos Linguísticos • Vitória (ES) •v. 11 •n. 29 • 2021 • ISSN: 2236-2592 • Dossiê temático $\bullet O$ texto na pesquisa e no ensino: conhecimentos, práticas e desafios na contemporaneidade •}

Fonte: ABAURRE, M. L. M; ABAURRE, M. B. M.; PONTARA, M. Português: contexto, interlocução e sentido. Vol. 2 São Paulo: Moderna, 2008, p. 378.

(6)

Figura 4 - Exemplo de explicação em livro didático (2)

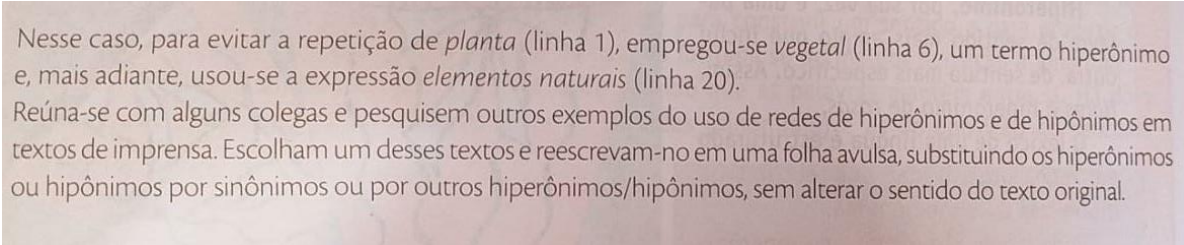

Fonte: FARACO, C. E.; MOURA, F. M.; MARUXO JÚNIOR, J. H. Língua portuguesa: linguagem e interação. Vol. 1 São Paulo: Ática, 2013, p. 208.

Nos dois exemplos, antes da explicação proposta, são apresentados os textos onde as expressões analisadas se encontram. O que chama atenção é a ênfase na natureza exclusivamente coesiva das expressões. Elas são compreendidas como elementos usados para a retomada classificada como substituição (especificando-se, em (6), a relação semântica hipônimo ou hiperônimo - entre os termos envolvidos na substituição).

Vale notar que, no período de publicação dos livros, a proposta da referenciação já gozava de certo prestígio na LT brasileira, de modo que os processos de reelaboração e negociação dos referentes, como condição fundamental da textualização, já poderiam fazer parte dos materiais didáticos. O que se vê é que essa atualização não ocorreu a contento nos anos 2010. Há, ainda, um caminho a ser percorrido. Esse caminho pressupõe assumir a referenciação como fenômeno textual-discursivo constitutivamente ligado à argumentação.

Na seção a seguir, apresentamos sugestões de práticas pedagógicas que julgamos mais condizentes com as perspectivas aqui assumidas.

\section{Referenciação calcada na argumentação - contribuições para a prática pedagógica}

A seguir, apresentamos duas propostas de atividades pedagógicas ${ }^{16}$ que julgamos representativas da ideia aqui assumida de que o ensino de estratégias de textualização, dentre as quais destacamos a referenciação, deve ser pautado por uma perspectiva que contemple a natureza argumentativa inerente aos textos, sendo as estratégias mecanismos reveladores dessa natureza. Na primeira atividade, focaliza-se a produção de um texto de visada argumentativa.

\footnotetext{
${ }^{16}$ Ambas as atividades estão presentes, com adaptações, em uma coleção didática a ser lançada, da qual este pesquisador é um dos autores. Elas são direcionadas ao $7^{\circ}$ ano do ensino fundamental e se incluem no campo da vida pública, mais especificamente, sobre as relações de consumo. Sobre os campos de atuação, ver o que recomenda a BNCC (BRASIL, s/d).
} 


\section{PERcursos Linguísticos • Vitória (ES) •v. 11 •n. 29 • 2021 • ISSN: 2236-2592 • Dossiê temático $\bullet O$ texto na pesquisa e no ensino: conhecimentos, práticas e desafios na contemporaneidade •}

Na segunda, mostra-se uma ação de compreensão textual para se perceber a dimensão argumentativa em um texto narrativo ${ }^{17}$.

Atividade 1 - referenciação na produção de texto de visada argumentativa

Você conhece os memes do tipo expectativa $\mathrm{X}$ realidade? Eles são construídos de modo a mostrar o contraste cômico entre a expectativa sobre uma situação desejada e a realidade percebida na situação concretizada.

Veja alguns exemplos de memes desse tipo. Nesses exemplos, as pessoas encomendaram um produto pela internet e tiveram uma "surpresinha" quando receberam a encomenda.

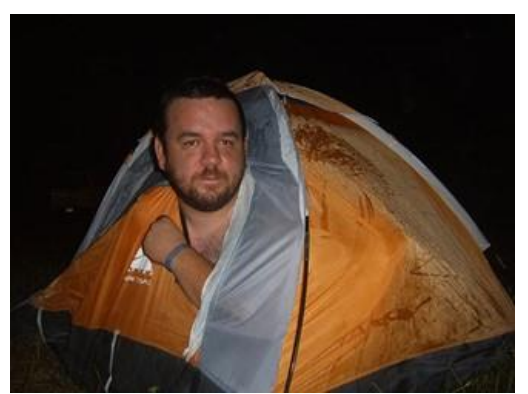

Expectativa: montar a barraca no sítio e dormir ao som do coaxar dos sapos e do canto dos grilos.

Realidade: você acaba descolando uma fantasia de Esfinge.
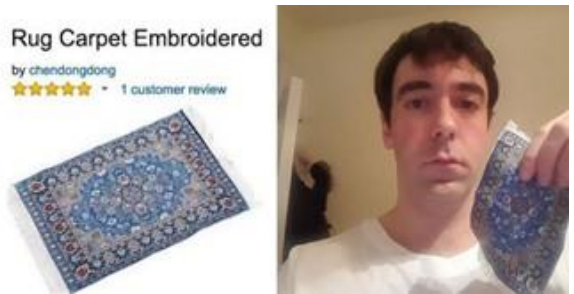

Expectativa: levantar da cama com o pé direito e pisar descalço em um tapete aveludado.

Realidade: você ganha um lenço com uma bela estampa.
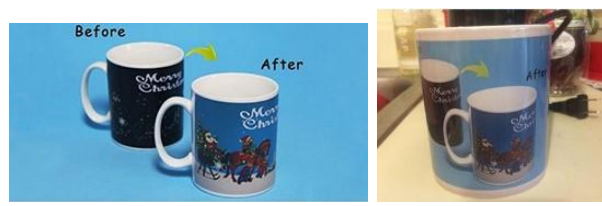

Expectativa: presentear a sua namorada com uma caneca natalina fotossensível. Realidade: ela ganha exatamente a caneca que foi anunciada.

Disponível em https://www.tecmundo.com.br/bizarro/106826-11-compras-feitasinternet-deram-errado.htm. Acesso em 7 abr. 2021.

Provavelmente, as pessoas envolvidas nesses memes devem ter ficado aborrecidas porque seu direito como consumidor não foi completamente atendido. Porém, ao mesmo tempo, parece que elas encararam a situação com uma dose de bom humor, pois revelaram suas histórias nas redes sociais.

${ }^{17}$ Não custa registrar que a escolha de uma prática de produção para tratar da visada argumentativa e de uma prática de compreensão para tratar da dimensão argumentativa não significa que haja os pares exclusivos "produção-visada" e "compreensão-dimensão". Óbvio é que atividades de produção que contemplem a dimensão argumentativa e atividades de compreensão sobre textos com visada argumentativa poderiam ser apresentadas. Caso o leitor tenha interesse em conhecer um exemplo de atividade que trata especificamente da distinção entre visada e dimensão argumentativas, sugerimos o trabalho de Abreu (2020). 


\section{PERcursos Linguísticos • Vitória (ES) •v. 11 •n. 29 • 2021 • ISSN: 2236-2592 • Dossiê temático $\bullet O$ texto na pesquisa e no ensino: conhecimentos, práticas e desafios na contemporaneidade •}

O humor pode ser uma forma eficaz de protesto. Por meio desse recurso, é possível estabelecer uma crítica sem parecer que se está chateado ou emocionalmente alterado. Isso contribui para que a crítica seja recebida de modo mais leve, o que talvez até possibilite que seja aceita mais facilmente.

A partir dessa ideia, sua tarefa será a de exercer seus direitos de consumidor usando o bom humor. Produza um texto de reclamação para uma empresa, a partir das instruções apresentadas a seguir.

- Sua reclamação pode partir de uma das situações mostradas nos memes, de uma situação que você ou alguém que conheça tenha vivido, ou de uma situação inventada por você. Caso precise de ideias para uma situação, uma busca pela internet pode ajudá-lo.

- Quando fizer o relato, tente ser original e engraçado. Pense em como você pode divertir as pessoas que lerão seu texto. Embora a audiência principal seja a empresa, outras pessoas também poderão ter acesso ao que você escrever.

- Defina qual será o estilo humorístico de seu texto. Duas estratégias comumente usadas são o pastelão e a ironia. O pastelão ocorre quando a situação é absurda ou exagerada, fora do comum. A ironia é utilizada para que haja um efeito implícito contrário ao que é dito; por exemplo, você pode apresentar expressões que aparentam revelar calma, quando, na verdade, está muito chateado.

- Procure se dirigir ao interlocutor (um suposto representante da suposta empresa) de modo gentil (irônico ou não).

- Se for necessário, escolha expressões que possam acentuar o humor do texto. Em um texto irônico, por exemplo, podem aparecer as expressões "encarecidamente", "humildemente", "prezado", "meus sinceros agradecimentos" etc.

- Lembre-se de apresentar informações detalhadas e organizadas.

- Lembre-se de fazer um pedido à empresa.

A atividade coloca o aluno para efetuar um projeto de dizer que passa pela proposição de uma tese: o produto/serviço recebido é defeituoso. O aluno, na posição de consumidor insatisfeito, deverá persuadir o interlocutor (a empresa vendedora do produto ou prestadora do serviço) a aderir a esta tese e, a partir disso, tomar uma decisão. Tem-se, portanto, uma prática pedagógica sobre um texto de visada argumentativa.

O aprendiz deverá lançar mão de estratégias que o permitam atingir o propósito elencado: fazer uma reclamação de consumo de modo bem-humorado. Para tanto, ao seguir às recomendações explicitadas nas instruções, e além delas, precisará dar atenção à construção de três referentes salientes na situação: o produto/serviço com problema, o consumidor (a imagem que criará de si mesmo, como sujeito insatisfeito que usa do humor para fazer sua queixa) e a empresa a quem se dirige.

Esses referentes, com as especificidades que terão, tomam corpo somente dentro desse texto, por isso a elaboração e negociação a ser efetivadas têm como limite de realização as possibilidades que a proposta de produção lhes garante (explícita ou implicitamente). Além disso, a criação do texto contará com uma organização textual particular do aluno, que tem espaço para imprimir suas marcas no texto. Dentre outros aspectos, ele deverá definir o tipo de 


\section{PERcursos Linguísticos • Vitória (ES) •v. 11 •n. 29 • 2021 • ISSN: 2236-2592 • Dossiê temático $\bullet O$ texto na pesquisa e no ensino: conhecimentos, práticas e desafios na contemporaneidade •}

produto que será foco da reclamação, o tipo de humor que usará e o modo como se dirigirá à empresa. Logo, estará assumindo o papel de sujeito agente.

Obviamente, os referentes acionados realizarão a coesão textual, mas, mais que isso, revelarão a orientação argumentativa do texto. Essa orientação será percebida, também, pela rede referencial que conecta o produto, o consumidor e a empresa, permitindo que essas três entidades se materializem de modo interdependente. Esse arcabouço pode servir de parâmetro para a avaliação do professor sobre o texto: o humor pretendido e a eficácia da argumentação dependem do modo como os referentes se estabelecem.

Vê-se, assim, que a prática sugerida se pauta por uma proposta em que o aluno se coloca como sujeito munido de estratégias para persuadir, dentre as quais se encontra a construção referencial. Acreditamos que as práticas pedagógicas com textos de visada argumentativa que se pautem pela integração das instâncias aqui elencadas, firmadas nos pressupostos da linguística textual, pode contribuir para o aprendizado eficaz das habilidades concernentes ao desenvolvimento da competência discursiva (BALTAR, 2004).

Atividade 2 - referenciação na compreensão da dimensão argumentativa de um texto A festa

Desatino do Sul parou para a festa que começou no dia em que Apolo Onze nasceu e depois não parou mais.

A casa de Apolo Dez e Madrugada vivia entupida de convidados que se espalhavam pelo salão, pelo jardim, pelo quintal, pelo pomar, ainda bem que o terreno era bem grande.

O pessoal das redondezas, e depois os de lugares mais distantes, todos vinham atraídos pelo evento. Passavam uns dias, se divertiam um pouco, e Desatino do Sul vivia disso.

Lá não se perdia tempo com outra coisa que não fosse festa.

Uma festa que não acabava nunca.

A festa do nascimento de Apolo Onze.

[...] Era tanto convidado que acabou se tornando obrigatória a presença de garçons para servir aquele pessoal todo. Olha aí. Não sei quantos novos empregos.

Todos os cantadores que existiam na cidade ainda eram poucos para tanta exigência de música.

Para os sapateiros, não faltava serviço, pois se tem coisa que acaba sapato é esse negócio de dançar em festa.

Os criadores de galinha ganhavam muito dinheiro: não sei quantos ovos para se fazer os doces, não sei quanto de miúdo, mais não sei quantos galetos.

A mulher do cachorro-quente vendia uma média de duzentos por dia, o que no final do mês dava uns seis mil e bastante.

$\mathrm{O}$ vendedor de amendoim quase não dava conta dos pedidos, quem não gosta de um amendoinzinho para acompanhar a besteira?

A cidade inteira vivia da festa.

O fornecedor de bebidas, o velhinho da confeitaria, a dona da butique, os floristas e, principalmente, os solteiros, as viúvas e os abandonados.

Dona Remédios da farmácia, por exemplo, passou a vender mais de quarenta sais de fruta por dia, além de uma quantidade enorme de xarope para o fígado, quadruplicando assim o seu faturamento. 


\section{PERcursos Linguísticos • Vitória (ES) •v. 11 •n. 29 • 2021 • ISSN: 2236-2592 • Dossiê temático $\bullet O$ texto na pesquisa e no ensino: conhecimentos, práticas e desafios na contemporaneidade •}

Como ninguém tinha motivo para chorar nunca, o fabricante de lenços resolveu lançar uma coleção especial de lenços com motivos festivos, que servissem para se usar nos cabelos, amarrar no pescoço ou enxugar o suor da dama, depois de uma música mais alegre.

[...] A única pessoa da cidade que não gostava da festa, pelo contrário, era o dono do pedaço que não pertencia aos Apolos.

Noctâmbulo (esse era o seu nome) tinha um pedação de terra e se achava muito importante por isso. [...]

Antes de Apolo Onze nascer e de começar a festa que tomou conta da cidade, Noctâmbulo contava com a população toda só para ele, não sei quantas mãos para servir de mão-de-obra.

Depois que a festa começou, o povo descobriu que podia trabalhar por conta própria e ainda se divertir, além de tudo.

Foi assim que ele perdeu, de uma só vez, todos os funcionários disponíveis no mercado.

[...] O que se sabe com certeza é que tudo que pode ser feito para acabar com uma festa, Noctâmbulo fez, pode apostar. Rogou praga, jogou pedra, acendeu vela, fez abaixo-assinado só com a sua assinatura, fez intriga, cara feia, desaforo, até que foi ao juiz reclamar do barulho e exigir uma solução.

O juiz foi averiguar, afinal era sua função, mas se divertiu tanto que terminou ficando lá. (Virou presidente do júri dos concursos de dança que aconteciam três vezes por dia e se sentia muito mais realizado profissionalmente do que antes). FALCÃO, Adriana. Luna Clara e Apolo Onze. São Paulo: Moderna, 2002, p. 20-24.

\section{Práticas de leitura ${ }^{18}$}

1. Participe da competição "Complete bem". Você deve preencher cada lacuna do comentário a seguir com uma palavra diferente. A pontuação para cada lacuna é a seguinte:

- se sua resposta não for coerente - 0 ponto;

- se sua resposta for coerente e dez ou mais pessoas escreverem a mesma palavra - 1 ponto;

- se sua resposta for coerente e cinco a nove pessoas escreverem a mesma palavra -2 pontos;

- se sua resposta for coerente e duas a quatro pessoas escreverem a mesma palavra -3 pontos;

- se sua resposta for coerente e somente você escrever a palavra - 5 pontos.

Antes de viverem sempre em festa, muitos dos moradores de Desatino do Sul eram empregados de Noctâmbulo e isso provavelmente os deixava

Com a vida girando em torno da festa, o sentimento dessas pessoas passou a ser de Além disso, particularmente para um grupo de cidadãos - o sapateiro, a mulher do cachorro-quente, o vendedor de amendoim, a dona da farmácia, entre outros -, a festa também trouxe

Entendemos que a atividade trabalha com a dimensão argumentativa inerente a todo texto. O que se coloca como tarefa é a interpretação de elementos de uma cena narrativa que implicam o reconhecimento de uma perspectiva colocada pelo narrador. A percepção sobre como a população de Desatino do Sul vivia antes e depois de a cidade girar em torno da festa revela determinado modo de encarar a vida, baseado na ideia de que as pessoas podem trabalhar

\footnotetext{
${ }^{18}$ A atividade contém outras questões de compreensão além da apresentada aqui.
} 


\section{PERcursos Linguísticos • Vitória (ES) •v. 11 •n. 29 • 2021 • ISSN: 2236-2592 • Dossiê temático $\bullet O$ texto na pesquisa e no ensino: conhecimentos, práticas e desafios na contemporaneidade •}

e se divertir ao mesmo tempo (e esse, na visão do narrador, parece ser o modo ideal de funcionamento de uma sociedade).

Para realizar essa compreensão de acordo com o molde que a questão coloca, o aluno que pretender ganhar mais pontos na competição deve preencher as lacunas com palavras menos usuais. Por exemplo, para a primeira lacuna, em vez de "tristes" ou "infelizes", pode-se usar "insatisfeitos" ou "desanimados"; para a segunda lacuna, em vez de "alegria" ou "felicidade", pode-se usar "euforia", "satisfação", "plenitude"; para a terceira lacuna, em vez de "dinheiro" ou "riqueza", pode-se usar "prosperidade", "lucro".

$\mathrm{Na}$ ação de completar, o aprendiz estará lidando com a construção dos referentes <habitantes de Desatino do Sul>, <profissões de Desatino do Sul ligadas à festa> e <Noctâmbulo>. De modo mais específico, está sendo abordada a recategorização dos moradores de Desatino do Sul. No texto, ao se confrontar o momento atual da cidade com o momento anterior, conclui-se que os habitantes, que hoje estão alegres, já estiveram infelizes um dia. O preenchimento das lacunas possibilita a reconstrução desse processo. Além disso, como na atividade anterior, esses referentes se ligam ao projeto de dizer do texto e devem ser compreendidos como partes de uma rede; é a relação entre eles no texto que permite a percepção de cada um como parte de um processo em que uma dada visão de mundo se apresenta.

A possibilidade de propor respostas diferentes para cada uma das lacunas indica que o processo de compreensão também se dá mediante a ação de sujeitos. Isso é verdade tanto nesse nível - em que se propõe uma interpretação e o aluno deve completá-la - quanto num nível mais elevado, mais próximo do que acontece práticas sociais efetivas de leitura - nas quais o leitor proficiente cria sua própria proposta de interpretação, a partir de elementos diversos, e fornece uma "resposta" ao texto.

A análise das duas atividades tem como objetivo mostrar que os pressupostos da linguística textual atual podem contribuir para a configuração de práticas pedagógicas eficazes. Para isso, é preciso concretizar as recomendações da BNCC (BRASIL, 2017), que coloca as práticas de leitura e produção, sempre inscritas numa dimensão discursiva, como ponto central das aulas de língua portuguesa. Dentre as diversas habilidades inerentes a essas práticas, a construção da referência, entendida como estratégia argumentativa, deve ocupar papel especial na condução das atividades.

\section{Considerações finais}




\section{PERcursos Linguísticos • Vitória (ES) •v. 11 •n. 29 • 2021 • ISSN: 2236-2592 • Dossiê temático $\bullet O$ texto na pesquisa e no ensino: conhecimentos, práticas e desafios na contemporaneidade •}

As ideias inscritas neste artigo partem de duas perspectivas que revelam novidades. De um lado, a proposta da linguística textual de descrever a configuração de qualquer texto a partir de uma base argumentativa. De outro, a necessidade de que as situações de ensino promovam o desenvolvimento de habilidades calcadas nos parâmetros que garantem a tessitura da coerência textual. Procuramos trabalhar com essas duas motivações a partir do fenômeno da referenciação, já que a construção de objetos de discurso é tributária do projeto de dizer de um locutor e resulta da negociação entre interlocutores, o que responde por parte significativa das relações geradoras de sentidos.

$\mathrm{Na}$ análise, ilustramos a aplicação pedagógica da referenciação em duas atividades, considerando seu papel na construção de textos de visada argumentativa, bem como na percepção da dimensão argumentativa de um texto narrativo. Salientamos que, em ambas as tarefas, os sentidos envolvidos na interação contam com a agentividade dos sujeitos. Acreditamos que a proposta exemplificada contém elementos que contribuem para a percepção de que o ensino de língua portuguesa pode se beneficiar do conhecimento teórico atualizado, quando este contribui para a confecção de momentos didáticos os quais propiciem ao aprendiz a ação sobre os textos.

Essa tônica vai ao encontro de uma concepção de professor o qual exerce seu papel de mediador altamente capacitado (GERALDI, 1997). Mais que fornecer explicações, esse profissional constrói situações em que a mobilização de recursos permitirá a sistematização de conhecimentos. Ao entender que a área de língua portuguesa ocupa um papel cada vez mais instrumental em vez de conteudístico, o professor propiciará as bases para que os estudantes possam desenvolver o que mais importa: os conhecimentos que os permitam interagir para argumentar e tentar modificar os modos de ver, pensar e sentir dos seus parceiros de comunicação.

\section{(7) Referências}

ABREU, Janieyre da Silva. Proposta para o ensino das relações discursivo-argumentativas em textos de alunos do ensino médio: um diálogo entre linguística textual e teoria da argumentação na língua. 2020. 188 f. Dissertação (Mestrado Profissional em Letras). Universidade Estadual do Ceará, Fortaleza, 2020.

ADAM, Jean-Michel. Textos: tipos e protótipos. São Paulo: Contexto, 2019.

AMOSSY, Ruth. Apologia da polêmica. São Paulo: Contexto, 2017. 


\section{PERcursos Linguísticos • Vitória (ES) •v. 11 •n. 29 • 2021 • ISSN: 2236-2592 • Dossiê temático $\bullet O$ texto na pesquisa e no ensino: conhecimentos, práticas e desafios na contemporaneidade •}

Argumentação e análise do discurso: perspectivas teóricas e recortes disciplinares. Tradução Eduardo Lopes Piris e Moisés Olímpio Ferreira. EID\&A, Ilhéus, n. 1, p. 129-144, nov. 2011.

ANTUNES, Irandé. Análise de textos: fundamentos e práticas. São Paulo: Parábola, 2010.

Aula de português: encontro e interação. São Paulo: Parábola, 2003.

APOTHÉLOZ, Denis; REICHLER-BÉGUELIN, Marie-José. Construction de la référence et strategies de designation. Tradução (inédita) Mônica Magalhães Cavalcante. In: BERRENDONNER, A.; REICHLER-BÉGUELIN, M.-J. (Org.). Du sintagme nominal aux objects-de-discours. Neuchâtsh: Université de Neuchâtsh, 1995, p. 227-271.

BALTAR, Marcos. A validade do conceito de competência discursiva para o ensino de língua materna. Linguagem em (Dis)curso - LemD, Tubarão, v. 5, n.1, p. 209-228, jul./dez. 2004.

BRASIL. Ministério da Educação. Base Nacional Comum Curricular. Brasília, DF: MEC, s/d.

CARVALHO, Ana Paula Lima de. Sobre intertextualidades estritas e amplas. 2018. 135f. Tese (Doutorado em Linguística). Universidade Federal do Ceará, Fortaleza, 2018.

CAVALCANTE, Mônica Magalhães. Referenciação: sobre coisas ditas e não ditas. Fortaleza: Edições UFC, 2011.

CAVALCANTE, Mônica Magalhães; BRITO, Mariza Angélica Paiva. O caráter naturalmente recategorizador das anáforas. In: AQUINO. Z. G. O.; GONÇALVES-SEGUNDO, P. R. (Org.). Estudos do discurso: caminhos e tendências. São Paulo: Paulistana, 2016, p. 119-133.

CAVALCANTE, Mônica Magalhães; CUSTÓDIO FILHO, Valdinar. Revisitando o estatuto do texto. Revista do Gelne. Teresina, v. 12, n. 2, p. 56-71, 2010.

CAVALCANTE, Mônica Magalhães; CUSTÓDIO FILHO, Valdinar; BRITO, Mariza Angélica Paiva. Coerência, referenciação e ensino. São Paulo: Cortez, 2014.

CAVALCANTE, Mônica Magalhães; et al. Linguística textual e argumentação. Campinas: Pontes, 2020.

CAVALCANTE, Mônica Magalhães; et al. O texto e suas propriedades: definindo perspectivas para análise. (Con)Textos Linguísticos, Vitória-ES, v. 13, n. 25, p. 25-39, 2019.

CAVALCANTE, Mônica Magalhães; et al. Desafios da Linguística Textual no Brasil. Intersecções, Jundiaí SP, v. 18, n. 1, p. 7-25, 2016. Disponível em http://www.portal.anchieta.br/revistas-e-livros/interseccoes/pdf/interseccoes-ano-9numero-1.pdf. Acesso em 16 set. 2021.

CORTEZ, Suzana Leite; KOCH, Ingedore. Villaça. A construção do ponto de vista por meio de formas referenciais. In: CAVALCANTE, M. M.; LIMA, S. M. C. (Org.). Referenciação: teoria e prática. São Paulo: Cortez, 2013, p. 9-29. 


\section{PERcursos Linguísticos • Vitória (ES) •v. 11 •n. 29 • 2021 • ISSN: 2236-2592 • Dossiê temático $\bullet O$ texto na pesquisa e no ensino: conhecimentos, práticas e desafios na contemporaneidade •}

CUSTÓDIO FILHO, Valdinar. Rediscutindo o princípio de construção negociada dos objetos de discurso. Revista de Letras, Fortaleza, v. 2, n. 36, p. 63-77, jul./dez. 2017.

Múltiplos fatores, distintas interações: esmiuçando o caráter heterogêneo da referenciação. 2011. 329f. Tese (Doutorado em Linguística). Universidade Federal do Ceará, Fortaleza, 2011.

FORTE, Jamille Saínne Malveira. Funções textual-discursivas de processos intertextuais. 2013. 129 f. Dissertação (Mestrado em Linguística). Universidade Federal do Ceará, Fortaleza, 2013.

GERALDI, João Wanderley. Portos de passagem. 4. ed. São Paulo: Martins Fontes, 1997.

KOCH, Ingedore Villaça. Referenciação e orientação argumentativa. In: KOCH, I. G. V.; MORATO, E. M.; BENTES, A. C. (Org.) Referenciação e discurso. São Paulo: Contexto, 2005, p. 33-52.

A coesão textual. 11. ed. São Paulo: Contexto, 1999.

KOCH, Ingedore Villaça; ELIAS, Vanda Maria. Escrever e argumentar. São Paulo: Contexto, 2018.

Ler e escrever: estratégias de produção textual. São Paulo: Contexto, 2009.

Ler e compreender: os sentidos do texto. 2. ed. São Paulo: Contexto, 2006.

KOCH, Ingedore Villaça.; BENTES, Anna Christina.; CAVALCANTE, Mônica Magalhães. Intertextualidade: diálogos possíveis. São Paulo: Cortez, 2007.

LIMA, Silvana Maria Calixto de. Entre os domínios da metáfora e da metonímia: um estudo de processos de recategorização. 2009. 204p. Tese (Doutorado em Linguística). Universidade Federal do Ceará, Fortaleza, 2009.

MATOS. Janaica Gomes. As redes referenciais na construção de notas jornalística. 259f. (Doutorado em Linguística). Universidade Federal do Ceará, 2018.

MONDADA, Lorenza; DUBOIS, Danièle. Construção dos objetos de discurso e categorização: uma abordagem dos processos de referenciação. Tradução Mônica Magalhães Cavalcante. In: CAVALCANTE, M. M.; BIASI-RODRIGUES, B.; CIULlA e SILVA, A. (Org.). Referenciação. São Paulo: Contexto, 2003, p. 17-52.

SÁ, Kleiane Bezerra de. Coerência e articulação tópica: uma análise a partir de redações do Enem. 2018. 260 f. Tese (Doutorado em Linguística). Universidade Federal do Ceará, Fortaleza, 2018.

SUASSUNA, Lívia. Ensino de língua portuguesa: uma abordagem pragmática. Campinas: Papirus, 1995. 